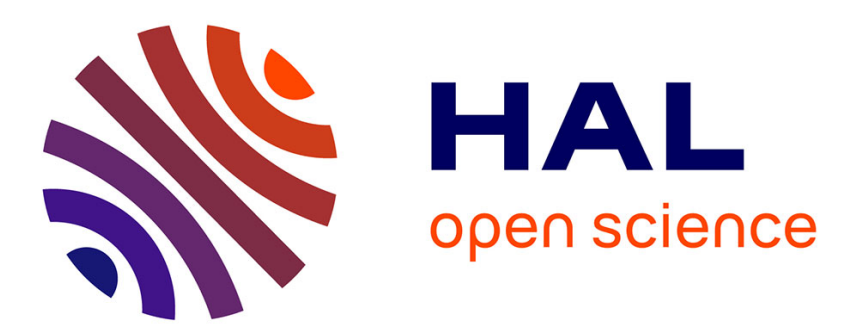

\title{
Correction of the water column attenuation: Application to the seabed sapping of the lagoon of New Caledonia using MERIS images
}

\author{
Audrey Minghelli-Roman, Cecile Dupouy
}

\section{- To cite this version:}

Audrey Minghelli-Roman, Cecile Dupouy. Correction of the water column attenuation: Application to the seabed sapping of the lagoon of New Caledonia using MERIS images. IEEE Journal of Selected Topics in Applied Earth Observations and Remote Sensing, 2014, 7 (6), pp.2619-2629. 10.1109/JSTARS.2014.2307956 . ird-01164845

\section{HAL Id: ird-01164845 \\ https://hal.ird.fr/ird-01164845}

Submitted on 18 Jun 2015

HAL is a multi-disciplinary open access archive for the deposit and dissemination of scientific research documents, whether they are published or not. The documents may come from teaching and research institutions in France or abroad, or from public or private research centers.
L'archive ouverte pluridisciplinaire HAL, est destinée au dépôt et à la diffusion de documents scientifiques de niveau recherche, publiés ou non, émanant des établissements d'enseignement et de recherche français ou étrangers, des laboratoires publics ou privés. 


\title{
Correction of the Water Column Attenuation: Application to the Seabed Mapping of the Lagoon of New Caledonia Using MERIS Images
}

\author{
Audrey Minghelli-Roman and Cécile Dupouy
}

\begin{abstract}
Features on the seabed can be mapped from remote sensing multi/hyperspectral imagery, provided that their effects on the measured reflectance spectrum can be made independent of those produced by the atmosphere and water column. The nonlinear effect of water column light attenuation can then be corrected to obtain the absolute reflectance of the seabed. Light attenuation by the water column and bathymetry are both determined from the satellite image. The water column attenuation is then removed in order to apply an automated supervised classification, whatever the depth is. We have compared the results obtained with and without the correction of water column attenuation, for two different statistical measures: Euclidean (ED) and spectral angle mapper (SAM) distances. We have applied this methodology to MERIS images acquired on the lagoon of New Caledonia. The best overall accuracy (79\%), as compared to in situ data, is obtained with the corrected image and the SAM distance.
\end{abstract}

Index Terms-Bathymetry, MERIS, seabed mapping, seabed reflectance, water column attenuation correction.

\section{INTRODUCTION}

$\mathrm{T}$ HE lagoon of New Caledonia is one of the three most extensive reef systems in the world, and UNESCO listed New Caledonia Barrier Reef on the World Heritage List under the name The Lagoons of New Caledonia: Reef Diversity and Associated Ecosystems on 7 July 2008 [1]. It features an exceptional diversity of coral and fish species and a continuum of habitats from mangroves to seagrass with the world's most diverse concentration of reef structures [2]. However, nickel mining in New Caledonia is a major sector of the New Caledonian economy, because the islands contain about $10 \%$ of the world's nickel reserves. With the annual production of about $138000 \mathrm{t}$, New Caledonia is the world's sixth largest producer, with $9 \%$ of the world production [3]. The mineral extraction process leads to massive erosion and brings important inputs of mineral matters into the fragile coastal ecosystem. This mining activity began more than 100 years ago, with important discharge and scattering of particles and metal deposit in the lagoon. We know that suspended particles have inhibiting effects on the reef communities through their abrasive capacity and the reduction in light penetration. Reef damage (bleaching and mortality) is enhanced during tropical storms in areas where land development has increased soil erosion [4]. Impacts of higher sediment inputs could induce alternative states of reef development [5], [6]. The authorities of New Caledonia must monitor turbidity, sediment inputs and sedimentation rates, given the mining developments that are now taking place on the island. These measurements are necessary within the Southern Lagoon of New Caledonia as well as in other sensitive spots such as Prony Bay (south of Grande Terre), the Havannah channel (Nouméa), in the Voh-KonéPouembout district, and around the protected marine areas.

Since 2000, researchers have been studying water composition and marine sediments, the currents responsible for the dispersion of land-based inputs, habitats, and marine diversity. This article proposes a method to map the lagoon bottom in order to evaluate the seabed cover change regarding the mining activity in the future.

In 1988, Chardy et al. [7] carried out a quantitative survey of the macrobenthos in the south-west lagoon of New Caledonia at 35 stations, sampled both with a grab and by diving. In 2000, Chevillon [8] also used an acoustic ground discrimination system (AGDS) in mapping complex and heterogeneous coral reef lagoon bottoms to assess the relationship between classically used sedimentological parameters and bottom acoustic classification, and to revisit the sedimentological structure of the SouthWestern lagoon of New Caledonia. Ouillon et al. [9] studied the circulation and suspended sediment transport in the coral reef lagoon (south-west of lagoon of New Caledonia) and used these maps containing percentage of mud content of suspended sediments on the same area. But these techniques do not allow the mapping of the whole seabed of the lagoon of New Caledonia.

The originality of this publication is that the water column light attenuation and the bathymetry can also be determined with the coarse resolution of MERIS imagery in order to correct the seabed reflectance from the water column attenuation and finally to map the seabed in the lagoon of New Caledonia. The MERIS sensor was designed for sea color observation, with a 300-m spatial resolution, 15 spectral bands, over a 1150-km swath width, and a 3-day revisit period [10], more adapted to monitor coastal zones than previous sensors such as SeaWifs (8 bands, 1-km resolution) or MODIS (8 bands, 500-m resolution). The spatial resolution of MERIS is here too coarse to map fine details of the lagoon bottom, but this disadvantage is balanced by its large swath $(1150 \mathrm{~km})$, which makes it possible to map the bottom of the whole lagoon of New Caledonia. 
In the literature, seabed mapping is largely used to map marine habitats. Mumby et al. [11] used aerial multispectral images to map the corals in the Turks and Caicos Islands. Andréfouët et al. [12] characterized the microbial mats in Rangiroa atoll using SPOT, ETM, and CASI. Fornes et al. [13] and Pasqualini et al. [14] mapped the Posidonia oceanica seagrass. Jaubert et al. [15] evaluated the extent of Caulerpa taxifolia development using airborne spectrographic remote sensing.

For a terrestrial landscape, classification (supervised or not) can directly be applied on the remote sensing images. For marine landscape, the problem is more difficult because the water column attenuates the seabed reflectance as a function of depth and water turbidity, and an automatic classification then cannot be applied without considering the water column attenuation and depth, because the variable total optical thickness of the water column depends on these two parameters.

Indeed, the above-surface reflectance derived by the sensor measurements $\left(\rho_{\mathrm{s}}\right)$, once corrected from the atmospheric effect, is a function of different parameters such as the water reflectance $\left(\rho_{\mathrm{w}}\right)$, the diffuse attenuation $\left(\mathrm{k}_{\mathrm{d}}\right)$, the seabed reflectance $\left(\rho_{\mathrm{b}}\right)$, and depth (z). The water reflectance is influenced by the water molecules as well as organic and inorganic components such as chlorophyll, suspended particulate matter (SPM), and colored dissolved organic material (CDOM). Pure water gradually absorbs light from the blue to the red spectral domain, but the other components contained in seawater modify the absorption and scattering as a function of their concentration: chlorophyll pigments increase the absorption in the blue and the red wavelengths, the SPM increases the scattering all over the visible domain, and the CDOM increases the absorption in the UV-blue domain. The water diffuse attenuation coefficient $\left(\mathrm{k}_{\mathrm{d}}, \mathrm{m}^{-1}\right)$ describes the spectral selective absorption and scattering due to water components [16]. The reflected radiation is then attenuated as a decreasing exponential function of water attenuation and depth as modeled by Maritorena [17]

$$
\rho_{s}(\lambda)=\left[\rho_{b}(\lambda)-\rho_{w}(\lambda)\right] e^{-2 k_{d}(\lambda) z}+\rho_{w}(\lambda)
$$

where $\rho_{\mathrm{s}}$ is the water surface reflectance, $\rho_{\mathrm{b}}$ is the bottom reflectance, $\rho_{\mathrm{w}}$ is the deep water reflectance, $\mathrm{k}_{\mathrm{d}}$ is the water diffuse attenuation, and $\mathrm{z}$ is the depth of the ocean bottom. All parameters, except z, are wavelength-dependent.

This question has been addressed by different studies. Lyzenga [18] proposed a method to eliminate the effect of water column attenuation on bottom radiance (or reflectance) using a unitless index image of bottom type (depth independent). This method was also used by Mumby et al. [11], but the drawback of this method is that index values cannot be related to radiance or reflectance measured in situ [12]. Durand et al. [19] chose to use a forward model to generate a synthetic library of surface reflectance with different depths, seafloor reflectance, and water composition inputs. Once the library is generated, each spectrum of the image is then compared to the spectral library to associate the optimum input parameters to this pixel. Some authors directly apply a classification because the depth is supposed to be constant [13]. Vahtmäe and Kutser [20] created different classes of same items at different depths. After a classification using the Euclidean (ED) distance, classes are merged.
Concerning the bathymetry, in the last decade, approaches in optically shallow water bodies have evolved to nonlinear optimization of semi-analytical models [21], [22] and comparative methods of spectral library matching [23], [24] from hyperspectral data and modeled data. These approaches, based on radiative transfer (RT) equations, are used to produce bathymetric maps and to quantify concentration of organic and inorganic water constituents.

Among the optimization of semi-analytical models, Lee et al. [21], [22] assumed that the seabed is covered by sand whose spectral profile was known with an unknown multiplicative coefficient. Several authors recently extended the method developed by Lee et al. by incorporating linear unmixing of the benthic cover. Giardino et al. [25] used two substrate classes (bare sand and submerged macrophytes) for the littoral zone of a lake, whereas Goodman and Ustin [26] and Klonowski et al. [27] integrated a semi-analytical inversion model with a linear unmixing of three known substratum types for coral reef environments.

Brando et al. [28] presented the quantitative comparison of model-derived depth for coastal water with high-resolution multibeam acoustic bathymetry data and showed that the precision of the bathymetry retrieval was a function of the contribution of substratum to the remote sensing signal. Adler-Golden et al. [29] combine atmospheric correction, water reflectance spectral simulations, and a linear unmixing bathymetry algorithm that accounts for water surface reflections, thin clouds, and variable bottom brightness, and can incorporate blends of bottom materials.

Concerning the comparative methods of spectral library matching, Mobley et al. [24] generated a Look Up Table of remote sensing reflectance (Rrs) with Hydrolight RT model. The range of input values (water composition and depth) needs to be sampled before simulations. The seabed reflectance present in the image also needs to be known. Hedley et al. [30] also chose this approach and optimized the searching process with the use of an adaptive linearized Look Up Tree. The drawback of this technique is the quantified output maps due to the model inputs sampling used to produce the Look Up Table. These last two approaches are known to be time-consuming (Dekker et al. [31]).

But the most noticeable drawback of these two approaches is the necessity of a priori knowledge of the bottom reflectance and the nondelivery of the real substratum reflectance. In this study, an inverse classical approach was preferred to remove from the image the influence of water attenuation due to the water column without knowledge of bottom reflectance. In other words, we try to remove the water layer on the seabed or "bring up" the seabed to the water surface and to provide for each pixel the attenuationcorrected spectrum of the bottom. This correction then allows to apply an automatic classification because a same item should now have the same reflectance, whatever the depth is. This method is even more interesting when the classification is operated using a spectral library, because it generally contains only one spectrum for each item, normalized from the depth. This last correction was then applied to MERIS images to map the seabed in the Southern part of the New Caledonia lagoon. Two important assumptions of the method used are the water clarity 
and the horizontal homogeneity. The choice of this method is here justified because these two assumptions are sometimes met in the New Caledonia lagoon. Additionally, pre-exiting knowledge on the water depth at a number of sites with known seabed type is also required.

In this paper, we applied a method for correcting the effects of water column attenuation on MERIS images, retrieving bathymetry, and classifying bottom types, using the lagoon of New Caledonia as a case study. Results obtained are presented with and without correction of the water column attenuation and with two different distances [ED distance and spectral angle mapper (SAM)]. The results are then discussed, and conclusion and perspectives are proposed.

\section{Site, METhOD, AND DATA}

\section{A. Site}

The New Caledonian lagoon (22177 km² , 25-m mean depth) lies in the South-Western Tropical Pacific from $20^{\circ}$ to $22 \mathrm{~S}$ and $166^{\circ}$ to $167^{\circ} \mathrm{E}$, with a heterogeneous bathymetry due to a complex geomorphology and a variety of different bottom colors. It is largely connected to the open ocean in the south part of the lagoon, but only by narrow passages in the south-west part of the lagoon. Exchanges with the sea can modify the phytoplanktonic assemblage in the central lagoon characterized by oligotrophic to mesotrophic waters (yearly average chlorophyll-a concentration of $0.25 \pm 0.01 \mathrm{rrgs} \cdot \mathrm{mn}^{-3}$ ) [32], [33]. With relatively low river inputs and a low turbidity range compared with other tropical lagoons (TSM concentrations ranging from 0.20 to $16 \mathrm{~g} \mathrm{~m}^{3}$, Ouillon et al. [32]), its trophic state is linked to spatial variations in flushing times [35], [36]. The variability of the turbidity was studied by Ouillon et al. [32] and the optical properties and chlorophyll concentration by Dupouy et al. [37].

\section{B. Method}

1) Oceanic Correction: Equation (1) needs to be inverted in order to estimate the bottom reflectance $\rho_{\mathrm{b}}$. Because $\rho_{\mathrm{w}}, \rho_{\mathrm{s}}, \mathrm{k}_{\mathrm{d}}$, and $\mathrm{z}$ can be deduced by different means that is detailed below, $\rho_{\mathrm{b}}$ can be estimated for each pixel and for each spectral band.

When the water is clear, an assumption can be made that the water is homogenous in the lagoon, and $\rho_{\mathrm{W}}$ and $\mathrm{k}_{\mathrm{d}}$ can then be considered as constant in the image. The attenuation can then be estimated by the measurement of sea surface reflectance of the same homogeneous items located at different depths as homogeneous sand. For each spectral band, sea surface reflectance of this same item can be plotted as a function of depth. This curve describes a decreasing exponential function that becomes, in natural logarithm, a line whose slope equals the attenuation $\left(k_{d}\right)$ in this band [18].

Deep water reflectance $\left(\rho_{\mathrm{W}}\right)$ can be directly measured in the image in an area too deep for the seabed to be of influence. In this area, $\mathrm{z}$ is high, seabed reflectance is out of influence, the first term of (1) is null, and the sea surface reflectance then equals the water reflectance $\left(\rho_{\mathrm{s}}=\rho_{\mathrm{w}}\right)$.

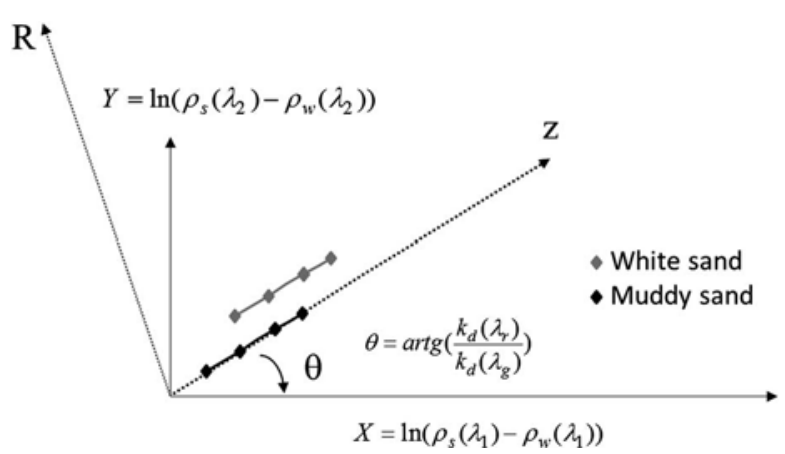

Fig. 1. Spectral rotation for bathymetric estimation [38].

Concerning bathymetry, the depth can be obtained by the combination of two spectral bands [38]. From (1) and (2), (3) can be deduced as

$$
\begin{aligned}
X= & \ln \left[\rho_{s}\left(\lambda_{1}\right)-\rho_{w}\left(\lambda_{1}\right)\right]=\ln \left[\mu_{l}\left(\lambda_{1}\right)-\rho_{w}\left(\lambda_{1}\right)\right]-2 k_{i_{l}}\left(\lambda_{1}\right) \\
Y= & \ln \left[\rho_{s}\left(\lambda_{L^{2}}\right)-\rho_{w}\left(\lambda_{2}\right)\right]=\ln \left[\rho_{b}\left(\lambda_{2}\right)-\rho_{w}\left(\lambda_{2}\right)\right]-2 k_{t}\left(\lambda_{2}\right) \\
Y= & \frac{k_{d}\left(\lambda_{2}\right)}{k_{d}\left(\lambda_{1}\right)} X+\ln \left[\rho_{b}\left(\lambda_{2}\right)-\rho_{w}\left(\lambda_{2}\right)\right] \\
& -\frac{k_{d l}\left(\lambda_{2}\right)}{k_{d}\left(\lambda_{1}\right)} \ln \left[\rho_{b}\left(\lambda_{1}\right)-\rho_{w}\left(\lambda_{1}\right)\right]
\end{aligned}
$$

where $\lambda_{1}<\lambda_{2}$. As MERIS has a high SNR ratio ( $\left.\sim 500\right)$, the surface reflectance is always higher than the deep water reflectance and the logarithm term is never negative. The depth expression ( $\mathrm{z}$ ) can be obtained from (2) and replaced in (3). Y can then be written as a linear expression of $\mathrm{X}(4)$ whose slope equals the attenuation ratio for the two wavelengths $\left(\mathrm{k}_{\mathrm{il}}\left(\lambda_{2}\right) / \mathrm{k}_{11}\left(\lambda_{1}\right)\right.$ ). This slope does not depend on the sea bottom cover $\left(\rho_{\mathrm{b}}\right)$, unlike the y-intercept.

When the two bands are projected on the two new axes (Fig. 1) obtained by rotation with an angle of $\mathrm{k}_{\mathrm{ll}}\left(\lambda_{2}\right) / \mathrm{k}_{11}\left(\lambda_{1}\right)$, we obtain two new images. This rotation aims at separating the influence of depth from other influences contributing to the measured reflectance (such as the seabed and the water color). One of the images is a depth-dependent image, linearly dependent on the underwater topography. Several pixels corresponding to different known depths are required to determine this linear relationship (see [38] for more details on the method). This calibration with true depths avoids the need of tidal correction.

In other words, because we assume the water to be homogenous, all the bottom reflectances are attenuated in the same way by the water column ( $\mathrm{k}$ is then the same for all the water pixels of the image). The variation of seabed reflectance is then only due to the depth. Fig. 1 explains this phenomenon. For one particular seabed such as sand, located at four different depths, points of this graph are aligned. For another seabed such as mud, located at four different depths, points of this graph will also be aligned and parallel to the first line because the attenuation parameter $\mathrm{k}$ is the same on the two seabeds, and this would be similar for all other seabeds. The rotation of the two bands then decorrelates the depth from the reflectance; one resulting band will be only depthdependent and the other will be only bottom reflectancedependent. 
With MERIS, different combinations are possible to constitute the pair of bands required to apply the method. The optimization of the pair of bands choice has been carried in a previous work [39]. All combinations with 13 bands were tested and the estimation results were compared with ground measurements. The best bathymetry estimates were obtained using a combination of MERIS blue (510 nm) and green $(560 \mathrm{~nm})$ bands. These bands are different from those advised by Philpot [38] [green (520-600) nm and red (630-690 nm) band] because he used Landsat/TM-MSS images and the choice in the bands selection was then limited. The signal-to-noise ratio was also too low to enable the use of the blue-green band. MERIS reaches 500 in signal-to-noise ratio, even in the blue with good atmospheric corrections allowing the choice of better bands. Finally, the bluegreen pair is more adequate than the green-red one, because the signal from the bottom is less attenuated in the blue and green regions than in the red one. If no signal from the bottom reaches the surface in the red band, the depth estimation cannot be operated especially in water that contains chlorophyll and sediments [16].

The attenuation, bathymetry, and deep water reflectance being defined, (1) can now be inverted in order to estimate the seabed reflectance $\left(\rho_{\mathrm{b}}\right)$ for all pixels

$$
\rho_{b}(\lambda)=\frac{\left[\rho_{H}(\lambda)-\rho_{w}(\lambda)\right]}{\rho^{-2 H_{v}(\lambda) z}} \dashv \rho_{w}(\lambda) .
$$

The corrected image then provides the bottom reflectance for each pixel. This image is now independent of the depth and an automatic classification can be applied to the corrected image.

2) Seabed Classification: The training samples were used to extract from the image the reference spectral profiles corresponding to the seabed substrate classes. All pixels of the image are then compared spectrally to these reference profiles and associated to the closest class in terms of spectral distance.

Two different statistical measures were applied to determine to which class a spectral profile belongs to: ED distance [40] and SAM distance [41]

$$
\begin{gathered}
E D(X, Y)=\sqrt{\frac{\sum_{i}^{n}[X(i)-Y(i)]^{2}}{n}} \\
S A M(X, Y)=\cos ^{-1}\left(\frac{\sum_{i-1}^{n}[X(i) \cdot Y(i)]}{\sqrt{\sum_{i=1}^{n} X(i)^{2}} \cdot \sqrt{\sum_{i=1}^{n} Y(i)^{2}}}\right)
\end{gathered}
$$

where $\mathrm{X}$ and $\mathrm{Y}$ correspond to two spectral profiles. $\mathrm{X}$ is the spectral profile of the class and $Y$ the spectral profile of the processing pixel. The pixels are associated to the closest class in terms of distance.

In fact, ED compares spectra in absolute value when SAM distance compares the shape of the spectra (in relative value).

To figure out the impact of the attenuation correction, the two classification distances are applied to the original image and to the image corrected from the attenuation. Fig. 2 presents a

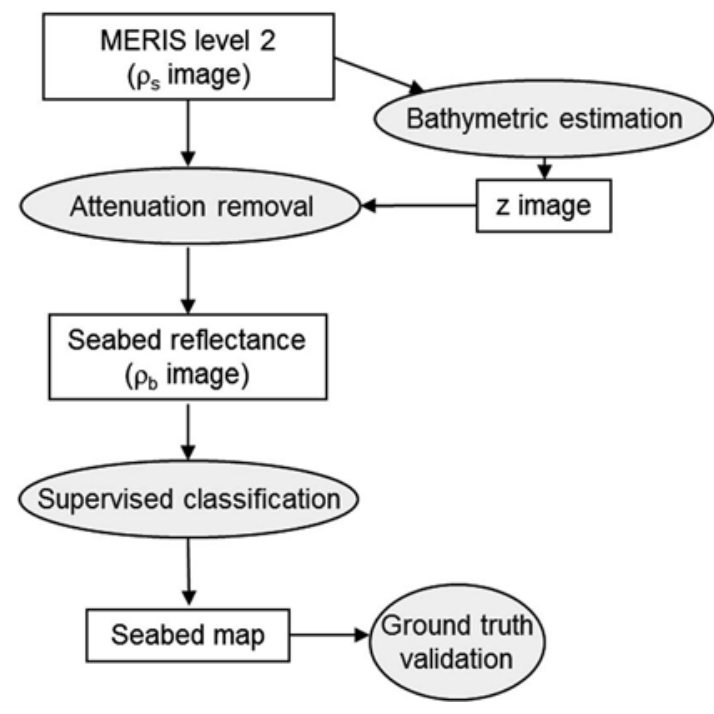

Fig. 2. Graphical representation of the methodology, with $\rho_{\mathrm{s}}$ the water surface reflectance and $\rho_{\mathrm{b}}$ the bottom reflectance.

graphical representation of the methodology (step-by-step flowchart).

3) Evaluation of the Method: The training and validation areas were obtained from the ground observations operated by Chardy et al. [7], Chevillon [8], and Ouillon et al. [9]. Their maps were co-registrated with the MERIS image, and the training and validation data were compared to each of these maps depending on the date of image acquisition. The confusion matrix can be analyzed to evaluate the performance of the classifications, with and without attenuation correction for both classification methods.

Finally, to show the consistency and usefulness of the method for change detection, we applied the method to another MERIS image acquired almost 5 years before the processed image (January 2004 and December 2008), and we analyzed the evolution.

\section{Data}

A level-2 MERIS image acquired on the 7 December 2008 over New Caledonia (Fig. 3) was used to map the seabed in the lagoon. This image has been chosen for the water clarity given by in situ measurements [39] in order to better discriminate the seabed features. This image corrected from the atmospheric effect (standard MERIS atmospheric corrections) contains above-surface reflectance $\left(\rho_{\mathrm{S}}\right)$. Only the first six bands of MERIS, respectively, centered at 412, 442, 490, 510, 560, and $620 \mathrm{~nm}$, were used in the frame of this study, because in the other bands, the reflectance of the seabed is absorbed by the water column.

For validation purposes, we used eight control points located all around the Southern part of the island to evaluate the quality of the bathymetric map (Fig. 4) and also used the data from a quantitative survey of the macrobenthos in the south-west lagoon of New Caledonia at 35 stations, sampled both with a grab and by diving [7]. In their work, stations were classified by multivariate analysis on the basis of their floral and faunal compositions and three major bottoms types: muddy sand, gray sand, and white sand. This map was updated with the map published by Chevillon et al. [8] and Ouillon et al. [9] established from 859 


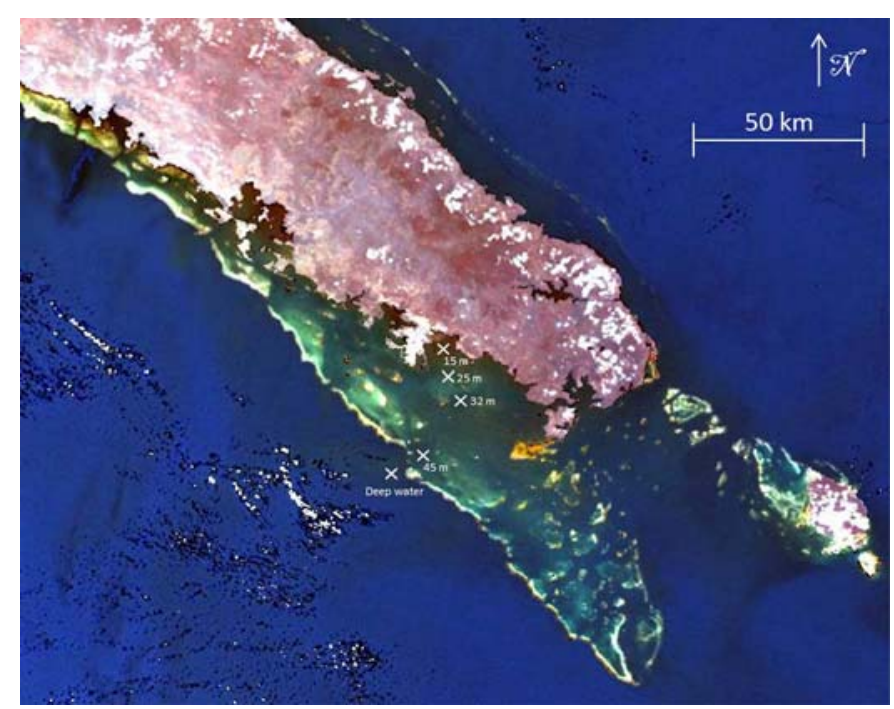

Fig. 3. Original MERIS image acquired on the 7/12/2008 on the Southern part of the New Caledonia Lagoon, color composite with bands 1, 3, and 5, and X represents ground training points for depth estimation.

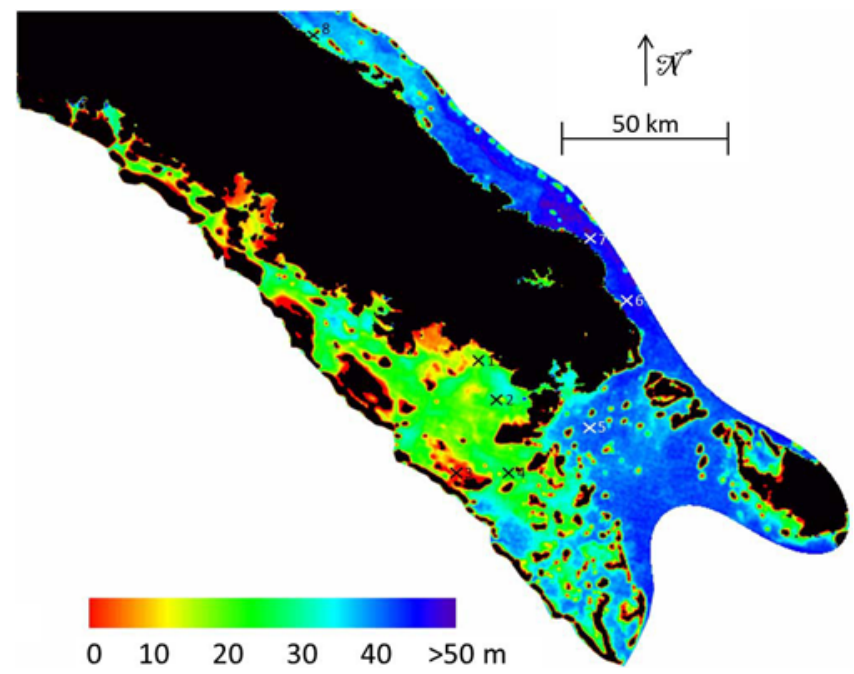

Fig. 4. Bathymetry resulting from the estimation model and ground control points for validation.

stations. Training and validation dataset can be localized in Fig. 5: small circles for training areas and polygons for validation areas. The training and validation samples contain three classes (muddy sand, gray sand, and white sand). The number of classes is limited to only three, because the resolution of MERIS is too coarse to identify algae and sea grass patches as well.

\section{RESULTS}

\section{A. Bathymetry}

Fig. 3 contains training locations for depth estimation, and Fig. 4 shows the resulting bathymetry map for the lagoon and the control points for validation. The color scale shows the deep water in dark blue and shallow water in white. When the water is clear, as in this image, the maximum depth that can be estimated is around $50 \mathrm{~m}$. This means that the estimation is only valid within the barrier reef of the lagoon of New Caledonia and this is the reason why the ocean is masked in Fig. 4.

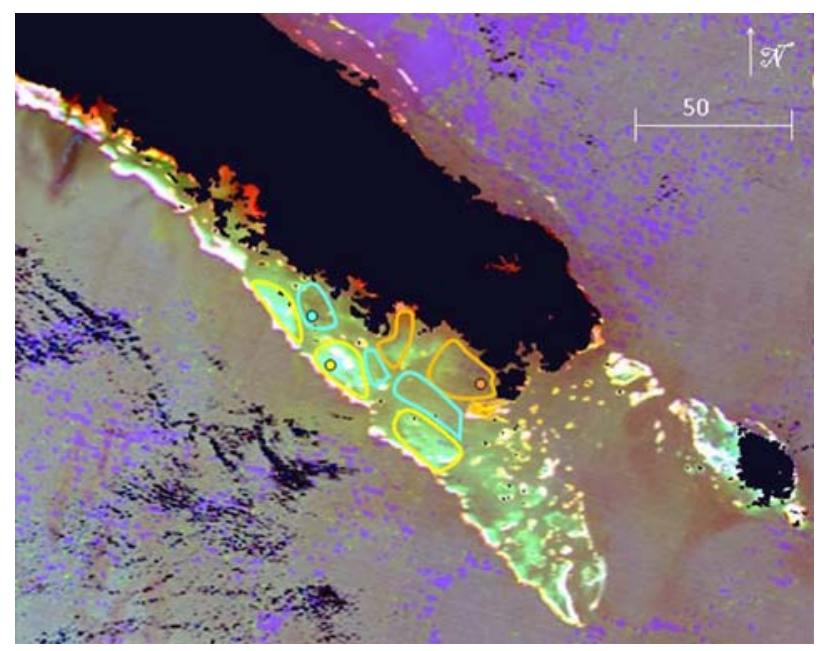

Fig. 5. Seabed reflectance resulting from the water column attenuation correction shown as color composite using MERIS bands 1, 3, and 5. ROI used for supervised classification: small circles for training areas and polygons for validation areas (yellow corresponding to white sand, orange to muddy sand, and cyan to gray sand).

The obtained bathymetry can be compared on the training locations (located in Fig. 3) in Table I, and on eight control points around "Grande Terre" island (located in Fig. 4) in Table II.

Table I shows that on the training locations, the depth is well estimated (RMSE of $3.55 \mathrm{~m}$ and a mean relative error at 11.6\%). On the eight control points, the error has increased compared to the training area; depth is often over-estimated. An explanation of the likely reasons for the observed deviations and their potential impact on the classification is provided in Section IV.

\section{B. Water Column Attenuation Correction}

Compared to Fig. 2, the water column correction has significantly reduced the effect of the water attenuation on the light reflected from the seabed (Fig. 5). The seabed appears now as if the water layer had been removed because a same item located at different depths now shows similar reflectance. The spectral profiles of the three different seabed items located by small circles in Fig. 5 are plotted in Fig. 6. These spectra correspond to white sand, gray sand, and muddy sand in the lagoon, and they were used as the training spectra for the supervised classification.

The correction of water column attenuation provides consistent spectra. For example, the white sand has a higher reflectance than the gray sand and the muddy sand (Fig. 6). If we compare these spectra with real reflectance spectra found in the literature [24], [28], and [31] between 400 and 575 nm, we can note the same behavior for white sand, gray sand, and muddy sand. Some weak spectral difference between pure white, gray, and muddy sand can be due to other elements in the sea bottom that cannot be discriminated by MERIS such as seagrass, algae, gravel, and corals. All of these elements can influence the spectral profile of our classes according to their proportion within the pixels. But, we did not consider the proportion of other classes in the major item because these classes are a minority and their proportion can vary from one pixel to another. We then prefer to calculate a mean spectrum for each class and then associate the similar pixels in terms of spectral distance to the same class. These three 
TABLE I

Absolute and Relative Error of Depth Estimation on the Training Locations (Located in Fig. 3)

\begin{tabular}{|l|l|l|l|l|c|}
\hline $\begin{array}{l}\text { Real depth } \\
(\mathrm{m})\end{array}$ & $\begin{array}{l}15.0 \\
(32 \mathrm{pts})\end{array}$ & $\begin{array}{l}25.0 \\
(32 \mathrm{pts})\end{array}$ & $\begin{array}{l}32.0 \\
(12 \mathrm{pts})\end{array}$ & $\begin{array}{l}45.0 \\
(12 \mathrm{pts})\end{array}$ & Mean \\
\hline $\begin{array}{l}\text { Depth } \\
\text { estimated }\end{array}$ & 13.4 & 27.2 & 35.8 & 39.6 & 3.5 \\
\hline $\begin{array}{l}\text { Difference } \\
(\mathrm{m})\end{array}$ & -1.6 & 2.5 & 3.7 & -5.5 & 11.6 \\
\hline $\begin{array}{l}\text { Relative } \\
\text { error }(\%)\end{array}$ & -10.3 & 10.1 & 11.7 & -12.1 & \\
\hline
\end{tabular}

TABLE II

Absolute and Relative Error of Depth Estimation on Eight Control Points (Located in Fig. 4)

\begin{tabular}{|l|c|c|c|c|}
\hline & Real depth $(\mathrm{m})$ & Depth estimated $(\mathrm{m})$ & Difference $(\mathrm{m})$ & Relative error $(\%)$ \\
\hline Point 1 & 22.3 & 25.1 & -2.8 & -12.51 \\
\hline Point 2 & 31.4 & 29.7 & 1.7 & 5.54 \\
\hline Point 3 & 13.8 & 15.5 & -1.6 & -11.86 \\
\hline Point 4 & 29.9 & 35.4 & -5.4 & -18.19 \\
\hline Point 5 & 59.0 & 48.3 & 10.7 & 18.14 \\
\hline Point 6 & 50.2 & 55.4 & -5.2 & -10.38 \\
\hline Point 7 & 50.0 & 57.5 & -7.5 & -15.06 \\
\hline Point 8 & 30.3 & 38.0 & -7.8 & -25.69 \\
\hline
\end{tabular}

TABLE III

Number of Training and Validation Pixels

\begin{tabular}{|c|c|c|c|}
\hline & Muddy sand & Gray sand & White sand \\
\hline Training pixels & 90 & 95 & 83 \\
\hline Validation pixels & 1780 & 2909 & 2977 \\
\hline
\end{tabular}

spectra are then used to classify seabed substrates into three different classes.

\section{Results of Classification}

Four different supervised classifications were applied with training samples. The training samples are defined by region of interest (ROI) (Table III, training pixels localized by small circles in Fig. 5) and not by spectral profiles interest in order not to penalize the classification on the different types of image. The first classification was applied to the original image (without correction) with the ED distance [Fig. 7(a)], whereas the second was applied on the corrected image with the same distance [Fig. 7(b)]. The SAM distance was also applied to the original [Fig. 7(c)] and the corrected image [Fig. 7(d)]. No other processing was applied on the classification results.

The classification results were then compared to the validation dataset (Table III, validation pixels located by polygons in Fig. 5) and the results are presented in Table IV. When the ED distance is applied to the original image, the overall accuracy, defined as percentage of correctly classified pixels, is the lowest (36.36\%) because the attenuation effect modifies the spectral profile as a function of depth. When the SAM distance is applied to the original image, the overall accuracy was improved (47.62\%) because the SAM distance compares the relative shape of the spectra and not the absolute reflected value. When the attenuation

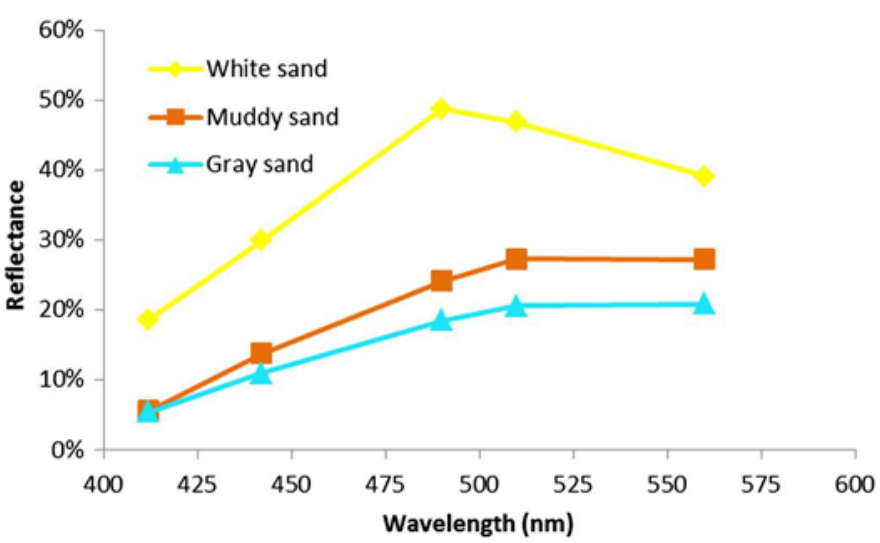

Fig. 6. Spectral profiles of major seabed items extracted from the corrected image (located by small circles in Fig. 5).

correction is applied, the classification with the ED distance was only slightly improved (40.13\%), but the best result was obtained by applying the SAM distance to the depth corrected image $(79.19 \%)$

\section{DISCUSSION}

Before discussing the results, we can summarize the limitations of using MERIS images. 


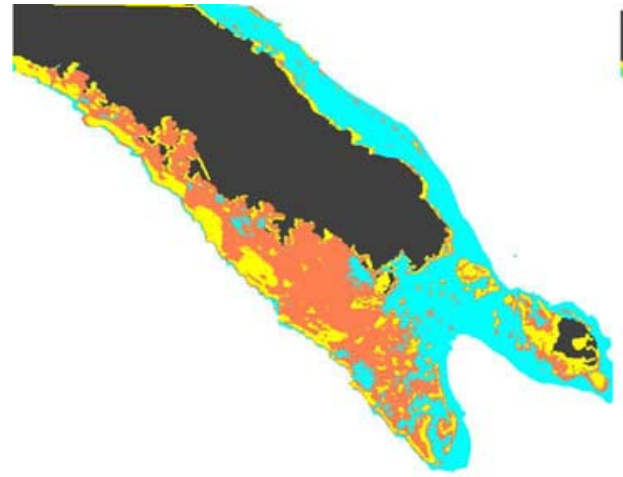

(a)

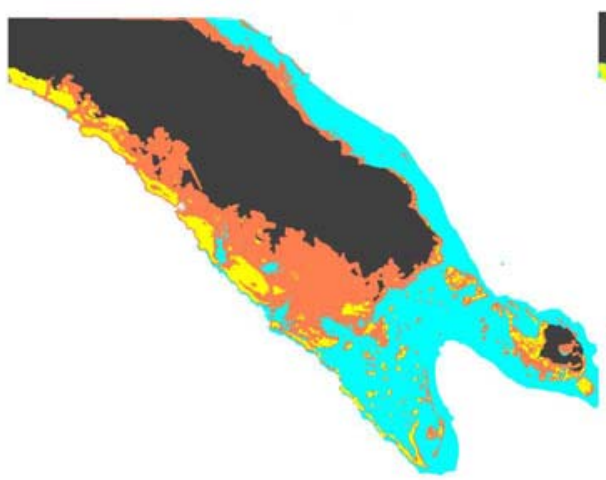

(c)

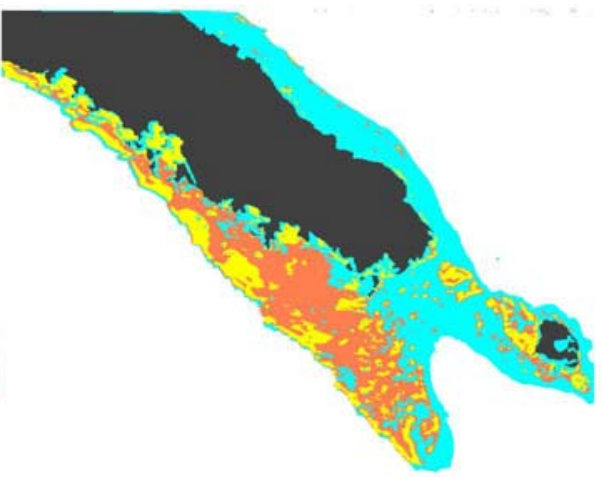

(b)

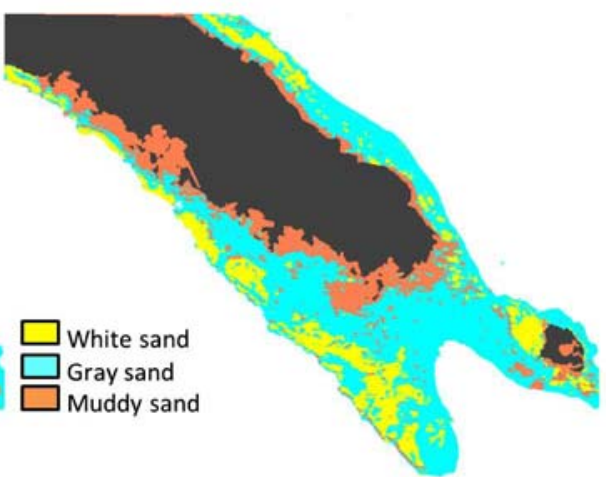

(d)

Fig. 7. Results of supervised classifications: (a) original image and ED distance, (b) water corrected image and ED distance, (c) original image and SAM distance, and (d) water corrected image and SAM distance.

1) The first limitation is the cloud cover, significant in tropical regions. In New Caledonia, even if MERIS provides two images per week, most of MERIS images are useless because of the cloud cover.

2) The second limitation can be the viewing angle because as the water reflectance is not lambertian, the viewing angle can have an influence on the error of seabed classification. Concerning the temporal comparison of two images not acquired on the same track, since the reflectance references are extracted in the image (ROI) instead of taking theoretical spectra for the classification, the error is then minimized. Concerning the viewing angle variation within one image, simulations with Hydrolight show that a variation of $34^{\circ}$ of viewing angle can lead to a variation of $20 \%$ in surface reflectance; it is then effectively important to limit the geographic area in order to limit the reflectance variation due to the viewing angle. In our study, in which we used MERIS images extraction, the variation of viewing is limited to $8^{\circ}$ leading to a surface reflectance variation of maximum $2 \%$ to limit the influence of viewing angle on the classifications.

3) Concerning the sunglint areas, MERIS processing removes the sunglint contribution to the ocean signal with the statistical method developed by Cox and Munk [42]. It uses external knowledge of the wind speed and direction and the illumination and observation geometry of each pixel, to estimate the level of sunglint contribution to the surface reflectance. When this contribution is below a "low threshold" value, the sunglint is neglected; when it is above that threshold and below a "high threshold," it is subtracted from the signal and a "medium glint" flag is raised; and when above the "high threshold," pixels are flagged as "high glint" and processed, even if the correction is less reliable. In case the correction yields negative values, it is disabled. The sunglint correction method uses a model which considers the sea surface as a collection of facets, each with individual slope components $\mathrm{z}_{\mathrm{x}}$ and $\mathrm{z}_{\mathrm{y}}$. The probability distribution of facet slopes $\mathrm{p}\left(\mathrm{z}_{\mathrm{x}}, \mathrm{z}_{\mathrm{y}}\right)$ depends on the wind speed and direction [42].

4) The surface roughness is the most difficult parameter to evaluate. It can be higher on deep water area than on shallow water, and a new error can then be introduced because as the water is not lambertian, the surface roughness can lead to a reflectance change. It can also increase the sunglint phenomenon and induce the apparition of foam. Because we did not have the information during the image acquisition, we then cannot evaluate the influence of the surface roughness on the water column correction that can dramatically decrease the signal of the surface reflectance by the addition of noise averaged in the signal at 300-m resolution. 
TABLE IV

Confusion Matrixes (in \%) Obtained With Supervised Classifications With and Without the Correction of Water Column Attenuation and With the ED or the SAM Distances

\begin{tabular}{|c|c|c|c|c|c|c|c|c|c|c|c|c|}
\hline Correction & \multicolumn{3}{|c|}{ Uncorrected } & \multicolumn{3}{|c|}{ Corrected } & \multicolumn{3}{|c|}{ Uncorrected } & \multicolumn{3}{|c|}{ Corrected } \\
\hline \multirow[t]{2}{*}{ Distance } & \multicolumn{3}{|c|}{ ED (\%) } & \multicolumn{3}{|c|}{ ED (\%) } & \multicolumn{3}{|c|}{ SAM (\%) } & \multicolumn{3}{|c|}{ SAM (\%) } \\
\hline & w.S. & G.S. & M.S. & W.S. & G.S. & M.S. & w.S. & G.S. & M.S. & W.s. & G.S. & M.S. \\
\hline White sand (W.S.) & 66.74 & 6.75 & 2.47 & 74.77 & 10.00 & 1.00 & 52.69 & 6.20 & 0.26 & 83.64 & 13.62 & 2.06 \\
\hline Grey sand (G.S.) & 0.01 & 0.08 & 32.58 & 0.00 & 2.44 & 33.53 & 3.41 & 17.74 & 1.63 & 1.68 & 66.56 & 0.60 \\
\hline Muddy sand (M.S.) & 100.00 & 93.17 & 64.95 & 25.23 & 87.56 & 65.47 & 43.90 & 76.06 & 98.11 & 16.36 & 19.82 & 97.34 \\
\hline Overall accuracy & \multicolumn{3}{|c|}{36.36} & \multicolumn{3}{|c|}{40.13} & \multicolumn{3}{|c|}{47.62} & \multicolumn{3}{|c|}{79.19} \\
\hline
\end{tabular}

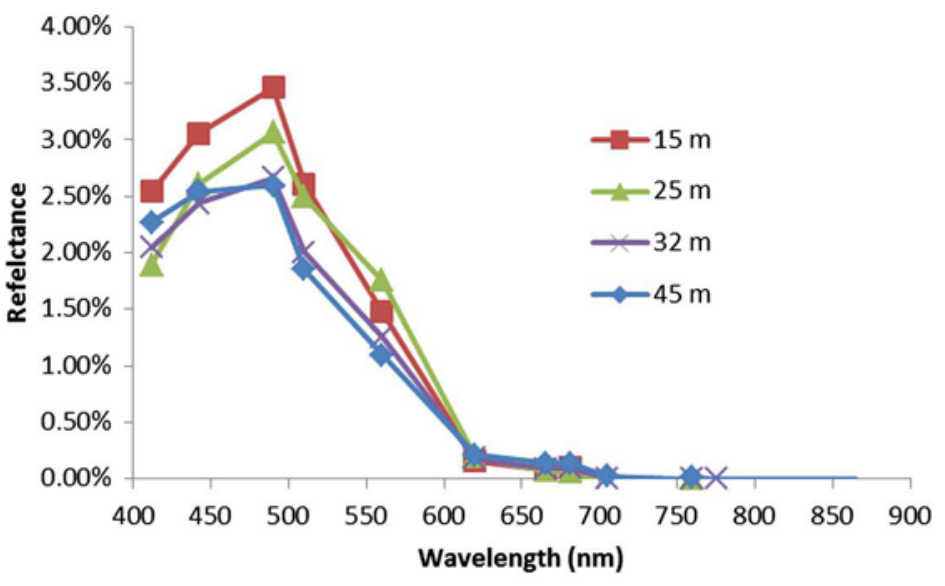

(a)

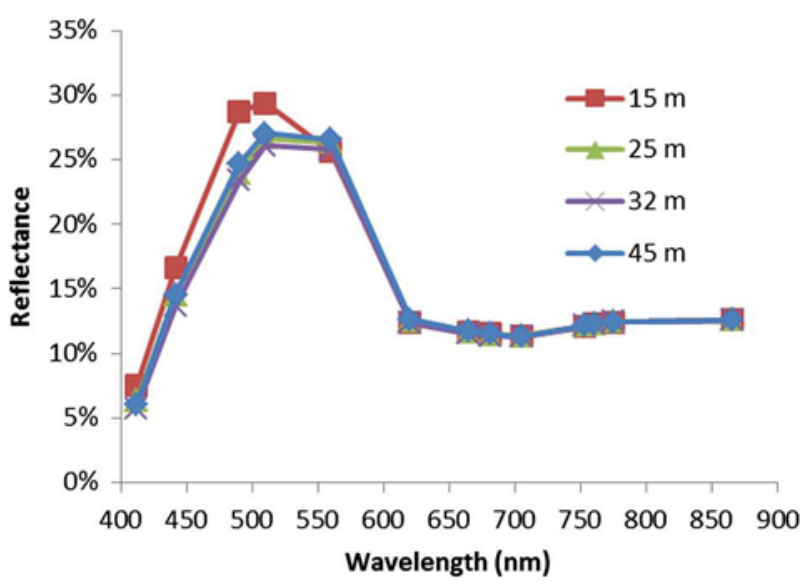

(b)

Fig. 8. Reflectance of sand patches of (a) sea surface reflectance and (b) retrieved bottom reflectance.

Concerning the water conditions, in the lagoon of New Caledonia, the trophic status of water ranges from oligotrophic to mesotrophic depending on the atmospheric conditions (rainfall, wind [43]). The choice of the image is then also fundamental as well for the bathymetry estimation and water column attenuation correction. The image from 3 December 2008 has been chosen because the water was relatively clear. Values of chlorophyll and suspended matter concentrations (measured in situ) varied, respectively, from 0.1 to $0.3 \mathrm{mg} \cdot \mathrm{m}^{-3}$ and from 0.2 to $0.6 \mathrm{mg} \cdot \mathrm{l}^{-1}$ in the lagoon [37], [44], [45]. The high water clarity was checked in the image: in the visible domain, we estimated an attenuation of $0.03 \mathrm{~m}^{-1}$ at $490 \mathrm{~nm}$ (MERIS band 3) in the training area (south-western lagoon).

In Table II, the depth estimation error on the eight control points around "Grand Terre" is higher than on the training area. This is due to the variation of attenuation, which means that the assumption of horizontal homogeneity was not fulfilled across the image. The depth is often over-estimated in regions where the attenuation is low, but when the error being under $30 \%$, the bathymetry remains valid for the water column correction.

Compared to RT methods, this technique provides similar accuracy because the fuller RT treatments reduce to (1) at large enough depths and because the reflectance ratios for the two spectral bands appear to be constant enough for the two-band bathymetry method to give satisfactory results. Dekker et al. [31] compared the different methods and showed that this kind of method breaks down in shallow water and when there is a large spectral variation among bottom types. However, in the case of this study, this method gives similar bathymetric accuracy to RT methods (around $11 \%$ in the training area and maximum 25\% out of this training area).

Concerning the attenuation correction, the bottom reflectance was then calculated by (4) according to the depth value. The same bottom type located at different depths should now have the same spectral profile. This result was checked on four sand patches located at different depths $(15,25,32$, and $45 \mathrm{~m})$. The ratio (standard deviation/mean averaged on the first five bands) of the gray sand patches reflectance is 0.15 with correction and 0.09 without correction. It means that the variation of the reflectance due to the depth is now reduced with the correction and this reduction was noticed for all the types of sand: white sand $(0.23 / 0.11)$ and muddy sand (0.18/0.10). In Fig. 8(a), the sea surface reflectance above sand patches located at different depths can be visualized. Fig. 8(b) shows the corresponding retrieved bottom reflectances, e.g., sand now displays very similar spectra, whatever the depth is. The difference at $15-\mathrm{m}$ depth is due to the increase of chlorophyll concentration and then of attenuation, the retrieved bottom reflectance is then here over-estimated.

When comparing the different classification results, if no correction is applied in the original image (Fig. 3), two same sand patches located at different depths offer different spectral profiles and may, therefore, apparently represent different seabed types. In contrast, two differing bottom types located at different depths may apparently belong to the same class (gray sand at low depth and white sand at high depth). This explains the low overall accuracy (36.36\%) obtained without attenuation correction and 


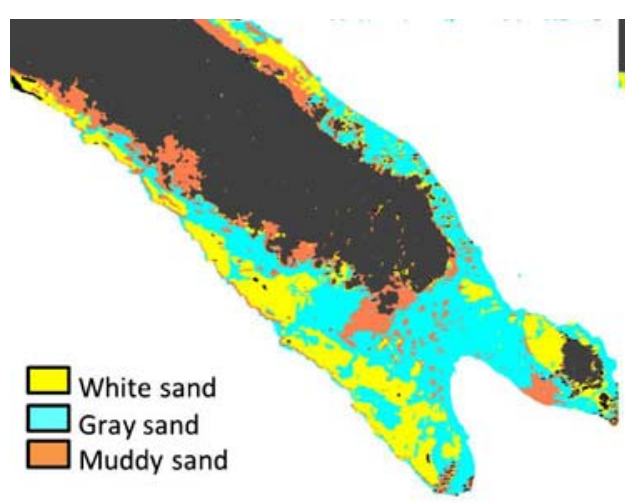

(a)

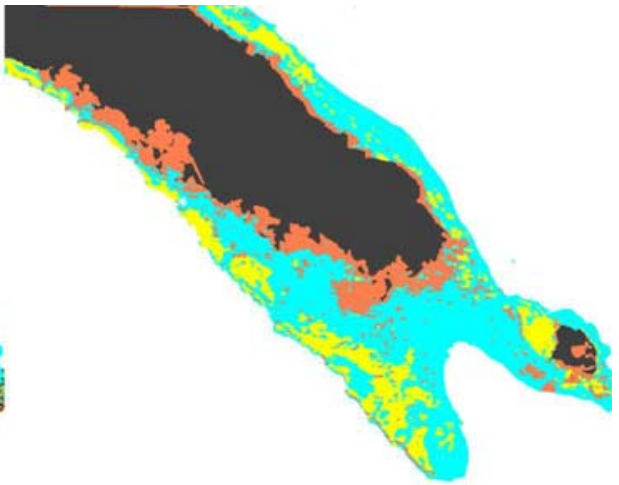

(b)

Fig. 9. Maps obtained from two MERIS images acquired: (a) 08/01/2004 and (b) 07/12/2008 (black areas represent clouds in the 2004 image).

with the ED distance. White sand and muddy sand are classified, respectively, with an accuracy of $66.74 \%$ and $64.95 \%$, whereas gray sand is almost entirely incorrectly classified (6.75\% classified as white sand and $93.17 \%$ classified as muddy sand).

If the water column correction is applied with the same ED distance, the overall accuracy increases but is not as high as expected (only 40.13\%). Only the white sand is better classified (accuracy of $74.77 \%$ ) but gray sand is still misclassified $(10.0 \%$ classified as white sand and $87.56 \%$ classified as muddy sand). This can be explained by the nonperfect attenuation correction with the assumption made on the attenuation homogeneity. The water is often clearer close to the reef than near the coasts due to river inputs that bring suspended matter. With the SAM distance, the overall accuracy is largely increased $(79.19 \%)$ because this distance measures the difference among spectral shapes rather than absolute values and then improves the results of classification. White, gray, and muddy sands are better classified (83.64, 66.56, and 97.34\%), and the omission (18.04, 33.44, and 2.66\%) are also strongly reduced.

We can now wonder if the SAM would be sufficient without attenuation correction. But the overall accuracy is only at $47.62 \%$ in that case. Gray sand is still classified as muddy sand (76.06\%) and white sand as muddy sand (43.90\%). The SAM distance alone cannot cancel the difference of reflectance due to water column attenuation. It only cancels a constant coefficient between two spectra. The correction of water column attenuation is then necessary, associated with the SAM distance.

If the best classification is now analyzed [Fig. 7(d)], the muddy sand is located close to the coast (due again to river input), the white sand is found around the small islands in the lagoon and in the large beds near the coral barrier reef and the gray sand is located between these two zones. This classification is in accordance with Chardy et al. [7], Chevillon et al. [8], and Ouillon et al. [9] determinations.

The over/under estimation of the bathymetry can affect attenuation correction; however, the choice of the SAM distance can minimize the impact of this error because it compares the spectra in terms of shape and not in absolute values. For the pixels whose depth and bottom type are known, we noticed that when the relative depth error is below 31\%, $100 \%$ of the pixels are well classified with the SAM distance. For the ED distance, misclassification begins when the relative depth error is higher than $16 \%$.
The error tolerance is then higher for the SAM distance than for the ED distance.

In order to show the consistency and usefulness of the method for change detection, we applied the method to another MERIS image acquired almost 5 years before the previous analyzed image, in the same summer season. Fig. 9 allows to compare the two maps.

Both images were acquired with different observation angles but since the bathymetry and attenuation were calculated independently for each image, the effect of the skewed view was minimized. This is shown by comparing our two images acquired with different observation angles, providing similar classification.

Between January 2004 and December 2008, muddy sand surfaces increased (from 22.1\% of the total surface in 2004 to $23.1 \%$ in 2008), the gray sand surfaces increased (from $51.2 \%$ in 2004 to $57.5 \%$ in 2008), and the white sand surfaces decreased (from 26.6\% in 2004 to 19.3\%). This statistics were calculated on pixels that are cloud-free on both dates. These changes can be due to the 2008 La Nina event, which caused rain levels over New Caledonia unreached since 1951 due to the intrusion of the cold equatorial tongue to the west inducing extensions of the warm pool (and rains) to the latitudes of New Caledonia and so, excess precipitations. Indeed, from March to May 2008, high turbidity impacts on lagoonal waters were observed on the coast during the ValHyBio cruise in March-April 2008 [44] and modeled by considering river inputs and coastal run offs [45], which could have led to the expansion of the coastal muddy areas.

\section{CONCLUSION}

In this article, we detailed a fast method based on the correction of water attenuation effect to map the seabed without a priori knowledge of the seabed reflectance. We used this method to map the seabed of the New Caledonian lagoon with MERIS images acquired during periods of oligotrophic waters typically encountered during summer months. We pointed out the importance of the choice of the SAM distance to map the seabed with accuracy. We also compared two maps obtained with two MERIS images acquired with an interval of 5 years. The two maps are similar with a low increase of muddy sand over the gray sand surfaces. Only three bottom types were classified in the image (white sand, gray sand, and muddy sand) because of the 
coarse resolution of MERIS sensor (300 m), which does not allow to map bottom types of typically smaller extensions such as corals, seagrass, and algae, but this resolution is balanced by the high swath that allows to map the whole seabed of the New Caledonia lagoon with only one MERIS image. An unmixing method (decomposition of mixed pixels) could probably improve the number of bottom types but the resolution of the map would not be improved; it could just provide the proportion of each bottom types within each pixel.

\section{ACKNOWLEDGMENTS}

The authors are grateful to the European Space Agency for providing the ENVISAT data used in this study (Project AOE.822) and thankful to the INSU-Programme National de Télédétection Spatiale VALHYBIO.

\section{REFERENCES}

[1] UNESCO, (2008). Lagoons of New Caledonia: Reef diversity and associated ecosystems [Online]. Available: http://whc.unesco.org/en/list/1115.

[2] P. Labrosse, R. Fichez, R. Farman, and T. Adams, Seas at the Millennium: An Environmental Evaluation: 2. Regional Chapters: The Indian Ocean to the Pacific, C.R.C. Sheppard, Ed. Boca Raton, FL, USA: CRC Press, 2000, pp. 723-736.

[3] USGS, (2011). Mineral community summary [Online]. Available: http:// minerals.usgs.gov/minerals/pubs/mcs/2011/mcs2011.pdf.

[4] J. S. Nowlis, C. Roberts, A. Smith, and E. Sirila, "Human-induced impacts of a tropical storm on nearshore coral reefs," Ambio, vol. 8, no. 26, pp. 515-521, 1997.

[5] C. J. McLaughlin, C. A. Smith, R. W. Buddemeier, J. D. Bartley, and B. A. Maxwell, "Rivers, runoff, and reefs," Global Planet. Change, vol. 39, pp. 191-199, 2003.

[6] I. A. Macdonald, C. T. Perry, and P. Larcombe, "Comment on "rivers, runoff, and reefs' by McLaughlin et al. [Global Planetary Change, 2003, vol. 39, pp. 191-199]," Global Planet. Change, vol. 45, pp. 333-337, 2005.

[7] P. Chardy, C. Chevillon, and J. Clavier, "Major benthic communities of the south-west lagoon of New Caledonia," Coral Reefs, vol. 7, pp. 69-75, 1988.

[8] C. Chevillon, "The use of seabed acoustic classification (RoxAnn) in indentifying the distribution of coral structures," in Proc. Int. Coral Reef Init. (ICRI), Noumea, New Caledonia, May 2000, pp. 22-24.

[9] S. Ouillon, P. Douillet, J. P. Lefebvre, J. P. R. Le Gendre, A. Jouon, P. Bonneton, J. M. Fernandez, C. Chevillon, O. Magand, J. Lefèvre, P. Le Hir, R. Laganier, F. Dumas, P. Marchesiello, A. Bel Madani, S. Andréfouët, J. Y. Panché, and R. Fichez, "Circulation and suspended sediment transport in a coral reef lagoon: The south-west lagoon of New Caledonia," Mar. Pollut. Bull., vol. 61, pp. 269-296, 2010.

[10] M. Rast, J. L. Bézy, and S. Bruzzi, "The ESA medium resolution imaging spectrometer MERIS-A review of the instrument and its mission," Int. J. Remote Sens., vol. 20, pp. 1681-1702, 1999.

[11] P. J. Mumby, E. P. Green, C. D. Clark, and A. J. Edwards, "Digital analysis of multispectral airborne imagery of coral reefs," Coral Reefs, vol. 17, pp. 59-69, 1998.

[12] S. Andréfouët, E. J. Hochberg, C. Payri, M. J. Atkinson, F. E. MullerKarger, and H. Ripley, "Multi-scale remote sensing of microbial mats in an atoll environment," Int. J. Remote Sens., vol. 24, pp. 2661-2682, 2003.

[13] A. Fornes, G. Basterretxea, A. Orfila, A. Jordi, A. Alvarez, and J. Tintore, "Mapping Posidonia oceanica from IKONOS," ISPRS J. Photogramm. Remote Sens., vol. 60, pp. 315-322, 2006.

[14] V. Pasqualini, C. Pergent-Martini, P. Clabaut, and G. Pergent, "Mapping of Posidonia oceanica using aerial photographs and side scan sonar: Application off the Island of Corsica (France)," Estuarine Coastal Shelf Sci., vol. 47, pp. 359-367, 1998.

[15] J. M. Jaubert, J. M. R. Chisholm, A. Minghelli-Roman, M. Marchioretti, J. H. Morrow, and H. T. Ripley, "Re-evaluation of the extent of caulerpa taxifolia development in the northern mediterranean using airborne spectrographic sensing," Mar. Ecol. Progr. Ser., vol. 263, pp. 75-82, 2003.

[16] N. G. Jerlov, Optical Oceanography, Elsevier Oceanography Series. Amsterdam, The Netherlands: Elsevier, 1968, p. 194.
[17] S. Maritorena, A. Morel, and B. Gentili, "Diffuse reflectance of oceanic shallow waters: Influence of water depth on bottom albedo," Limnol. Oceanogr., vol. 37, pp. 1689-1703, 1994.

[18] D. L. Lyzenga, "Remote sensing of bottom reflectance and water attenuation parameters in shallow water using aircraft and Landsat data," Int. J. Remote Sens., vol. 2, pp. 71-82, 1981.

[19] D. Durand, J. Bijaoui, and F. Cauneau, "Optical remote sensing of shallowwater environment parameters: A feasibility study," Remote Sens. Environ., vol. 73, pp. 152-161, 2000.

[20] E. Vahtmäe and T. Kutser, "Mapping bottom type and water depth in shallow coastal waters with satellite remote sensing," J. Coastal Res., vol. 50, pp. 185-189, 2007.

[21] Z. Lee, K. L. Carder, C. D. Mobley, R. G. Steward, and J. F. Patch, "Hyperspectral remote sensing for shallow waters: 2. Deriving bottom depths and water properties by optimization," Appl. Opt., vol. 38, pp. 3831-3843, 1999.

[22] Z. Lee, K. L. Carder, R. F. Chen, and T. G. Peacock, "Properties of the water column and bottom derived from airborne visible imaging spectrometer (AVIRIS) data," J. Geophys. Res. Ocean, vol. 106, pp. 11639-11651, 2001.

[23] E. M. Louchard, R. P. Reid, F. C. Stephens, C. O. Davis, R. A. Leathers, and T. V. Downes, "Optical remote sensing of benthic habitats and bathymetry in coastal environments at Lee Stocking Island, Bahamas: A comparative spectral classification approach," Limnol. Oceanogr., vol. 48, pp. 511-521, 2003.

[24] C. D. Mobley, L. Sundman, C. O. Davis, J. H. Bowles, T. V. Downes, R. A. Leathers, M. J. Montes, W. P. Bisset, D. D. R. Kohler, R. P. Reid, E. M. Louchard, and A. Gleason, "Interpretation of hyperspectral remotesensing imagery by spectrum matching and look-up tables," Appl. Opt., vol. 44, pp. 3576-3592, 2005.

[25] C. Giardino, M. Bartoli, G. Candiani, M. Bresciani, and L. Pellegrini, "Recent changes in macrophyte colonisation patterns: An imaging spectrometry-based evaluation of the southern Lake Garda (northern Italy)," J. Appl. Remote Sens., vol. 1, p. 011509, 2007.

[26] J. Goodman and S. L. Ustin, "Classification of benthic composition in a coral reef environment using spectral unmixing," J. Appl. Remote Sens., vol. 1, p. 011501, 2007.

[27] W. M. Klonowski, P. R. Fears, and M. J. Lynch, "Retrieving key benthic cover types and bathymetry from hyperspectral imagery," J. Appl. Remote Sens., vol. 1, p. 011505, 2007.

[28] V. E. Brando, J. M. Anstee, A. G. Wettle, M. Dekker, S. R. Phinn, and C. Roelfsema, "A physics based retrieval and quality assessment of bathymetry from suboptimal hyperspectral data," Remote Sens. Environ., vol. 113, pp. 755-770, 2009.

[29] S. M. Adler-Golden, P. K. Acharya, A. Berk, M. W. Matthew, and D. Gorodetzky, "Remote bathymetry of the littoral zone from AVIRIS, LASH, and QuickBird imagery," IEEE Trans. Geosci. Remote Sens., vol. 43, no. 2, pp. 337-347, Feb. 2005.

[30] J. Hedley, C. Roelfsema, and S. R. Phinn, "Efficient radiative transfer model inversion for remote sensing applications," Remote Sens. Environ., vol. 113, pp. 2527-2532, 2009.

[31] A. G. Dekker, S. R. Phinn, J. Anstee, P. Bissett, V. E. Brando, B. Casey, P. Fearns, J. Hedley, W. Klonowski, Z. P. Lee, M. Lynch, M. Lyons, C. Mobley, and C. Roelfsema, "Intercomparison of shallow water bathymetry, hydro-optics, and benthos mapping techniques in Australian and Caribbean coastal environments," Limnol. Oceanogr.: Methods, vol. 9, pp. 396-425, 2011.

[32] J. Neveux, M. Tenorio, S. Jacquet, J. P. Torreton, P. Douillet, S. Oouillon, and C. Dupouy, "Chlorophylls and phycoerythrins add markers of environmental forcings including cyclone erica effect (March 2003) on phytoplankton in the SouthWestern lagoon of New Caledonia and oceanic adjacent area," Int. J. Oceanogr., vol. 2009, Art. ID 232513, 19 pp., 2009, doi: $10.1155 / 2009 / 232513$.

[33] S. Jacquet, B. Delesalle, J. P. Torréton, and J. Blanchot, "Response of phytoplankton communities to increased anthropogenic influences (southwestern lagoon, New Caledonia)," Mar. Ecol. Progr. Ser., vol. 320, pp. 65-78, 2006, doi: 10.3354/meps320065.

[34] S. Ouillon, P. Douillet, A. Petrenko, J. Neveux, C. Dupouy, J. M. Froidefond, S. Andréfouët, and A. Muñoz-Caravaca, "Optical algorithms at satellite wavelengths for total suspended matter in tropical coastal waters," Sensors, vol. 8, pp. 4165-4185, 2008, doi: 10.3390/ sensors.

[35] A. Jouon, P. Douillet, S. Ouillon, and P. Fraunié, "Calculations of hydrodynamic time parameters in a semi-opened coastal zone using a 3D hydrodynamic model," Cont. Shelf Res., vol. 26, no. 12-13, pp. 1395-1415, 2005. 
[36] J. P. Torréton, E. Rochelle-Newall, A. Jouon, V. Faure, S. Jacquet, and P. Douillet, "Correspondence between the distribution of hydrodynamic time parameters and the distribution of biological and chemical variables in a semi-enclosed coral reef lagoon," Estuarine Coastal Shelf Sci., vol. 74, pp. 667-677, 2007.

[37] C. Dupouy, J. Neveux, S. Ouillon, R. Frouin, H. Murakami, S. Hochard, and G. Dirberg, "Inherent optical properties and satellite retrieval of chlorophyll concentration in the lagoon and open ocean waters of New Caledonia," Mar. Pollut. Bull., vol. 61, pp. 503-518, 2010.

[38] W. D. Philpot, "Bathymetric mapping with passive multispectral imagery," Appl. Opt., vol. 28, pp. 1569-1578, 1989.

[39] A. Minghelli-Roman, A. Goreac, S. Mathieu, M. Spigai, and P. Gouton, "Comparison of bathymetric estimation using different satellite images in coastal sea waters,” Int. J. Remote Sens., vol. 30, pp. 5737-5750, 2009.

[40] L. Wang, Y. Zhang, and J. Feng, "On the Euclidean distance of image," IEEE Trans. Pattern Anal. Machine Intell., vol. 27, no. 8, pp. 13341339, Aug. 2005.

[41] N. Keshava, "Distance metrics and band selection in hyperspectral processing with applications to material identification and spectral libraries," IEEE Trans. Geosci. Remote Sens., vol. 42, no. 7, pp. 1552-1565, Jul. 2004.

[42] C. Cox and W. Munk, "Statistics of the sea surface derived from sun glitter," J. Mar. Res., vol. 13, pp. 198-227, 1954.

[43] C. Dupouy, G. Wattelez, R. Fuchs, J. Lefèvre, M. Mangeas, H. Murakami, and R. Frouin, "The colour of the Coral Sea," in Proc. 12th Int. Coral Reef Symp., Cairns, Australia, Jul. 2012, pp. 9-13, ICRS2012-18E_02.

[44] C. Dupouy, R. Frouin, R. Röttgers, J. Neveux, F. Gallois, J. Y. Panché, P. Gérard, C. Fontana, C. Pinazo, S. Ouillon, and A. Minghelli-Roman, "Ocean color response to an episode of heavy rainfall in the lagoon of New Caledonia," in Ocean Remote Sensing: Method and Applications, Proc. SPIE, vol. 7459, R. J. Frouin, Ed. Bellingham, WA, USA: SPIE, 2009, 10pp, 7459-15.

[45] R. Fuchs, C. Dupouy, P. Douillet, M. Caillaud, A. Mangin, and C. Pinazo, "Modelling the impact of a La Niña event on a South West Pacific Lagoon," Mar. Pollut. Bull., vol. 64, pp. 1596-1613, 2012. 